\title{
Investigation of the Aerodynamic Drag Force Exerted on a Powerboat
}

\author{
Zbigniew Czyż ${ }^{*}$, Paweł Karpiński², Chahin Boujelbene ${ }^{3}$ \\ 1 Faculty of Aviation, Military University of Aviation, ul. Dywizjonu 303 35, 08-521 Dęblin, Poland \\ 2 Department of Thermodynamics, Fluid Mechanics and Aviation Propulsion Systems, Faculty of Mechanical \\ Engineering, Lublin University of Technology, ul. Nadbystrzycka 36, 20-618 Lublin, Poland \\ 3 Department of Electromechanic, Thermal Machinery and Shipbuilding, Sfax University, National Engineering \\ School of Sfax, Route de l'Aéroport Km 0.5 BP 1169.3029 Sfax, Tunisia \\ * Corresponding author's e-mail: z.czyz@law.mil.pl
}

\begin{abstract}
The aerodynamics of powerboats used in inshore powerboat racing has a significant impact on their performance. The aerodynamic drag forces generated on individual elements of this type of boats were tested. The solid model of the boat developed in the CAD software was used for the calculations. The computational grid was generated, as well as the boundary conditions and the turbulence model, were determined. On the basis of such assumptions, the numerical calculations were carried out using the CFD method. The results from the numerical simulations consist of a description of the velocity and pressure distribution around the tested object and identification of the drag force on the components of the powerboat with a description of the relationship between them. Additionally, the variation of the drag force as a function of speed in the range from 0 to $60 \mathrm{~m} / \mathrm{s}$ was presented. The tests were performed for 5 values of the angle of attack of the boat to the surface of water in the range from $0^{\circ}$ to $12^{\circ}$. The scope of the research allowed for the development of a drag force map depending on the defined parameters. The test results can be used to optimize the shape of the boat structure in order to reduce the aerodynamic drag generated on its individual elements.
\end{abstract}

Keywords: aerodynamics, boat, CFD, drag force, powerboat.

\section{INTRODUCTION}

Some of the scientific publications devoted to the study of ships and boats are focused on the analysis of their stability. Paper [9] presents a mathematical model of the movement of a boat along the river, taking into account the external conditions: the influence of wind and water currents on the boat's movement. In addition, researchers concentrate their work on the analysis of the boat structure stresses. An example of such a work is [15] where a method of designing hulls is presented, taking into account the phenomenon of slamming.

In the case of race powerboats and go-fast boats, the hydrodynamic phenomena are accompanied by the aerodynamic ones, which play a major role in performance. This is due to the fact that when moving at high velocity, the contact of the boat with water is significantly reduced, so the drag force is largely generated by the interaction with air. In addition, a tunnel hull is commonly used in race powerboats. As a result of the air flow through the central tunnel, the aerodynamic lift is generated which, together with the buoyancy force, affects the ship. The value of the resulting aerodynamic force is closely related to the ground effect. It is, therefore, necessary to conduct the aerodynamic drag tests on individual components of sport boats.

One of the methods of aerodynamic testing of an object is to place it in the wind tunnel [18]. An example of such a test method includes the aircraft tests [1], in which the aerodynamic forces and the moments acting on the structure were determined. Due to the size of the boat, it 
is recommended to use its scaled model for research (there are very few tunnels capable of examining such an object on a scale of $1: 1$, and the costs of such research are too high). This method was used by the authors in the paper [10] in which the aerodynamics and stability of the sail-assisted ship model were investigated.

The scaling problem does not occur when using the CFD (Computational Fluid Dynamics) method. This method is based on the numerical solution of partial differential equations describing the flow of fluid in the studied area. The Navier-Stokes equations taking into account the principle of conservation of momentum, mass and energy are used. As a result of such calculations, the distributions of velocity, pressure and other thermodynamic parameters in the studied area are obtained. The CFD method is used in many areas of research on flow issues $[3,19,2$, 17]. An example of using this method for analyzing aerodynamic lift and drag performance of the airship is work [11].

In today's aerodynamic research, many measurement techniques are used. Currently, the synergy of experimental research and numerical calculations for a validation of developed models is a significant trend [7].

An example of a work in which the CFD test method was used for an analysis of the aerodynamic drag is the paper [6] in which the drag force generated on the individual elements of the gyrocopter structure was examined. This method can also be used for a hydrodynamic research of the ship or its elements, as shown in [14] and [22]. An alternative method to the CFD technique and one of the most common methods to visualize the medium flow is Particle Image Velocimetry (PIV). This is an optical method for a qualitative visualization and a quantitative measurement of speed, e.g. of air around a research area. This method is described in [8].

Numerical calculations can also be used to optimize the boat hull shape to reduce its aerodynamic drag and improve its performance. An example of such an approach are the studies in [5] that aimed at optimizing the ship hull shape by means of a parameterization and deformation analysis of various types of the hull shape based on a frame construction. On the other hand, the paper in [16] presents the results of the CFD calculations of cooling the aircraft engine which show that the hull geometry has a significant impact on the cooling conditions of the engine.
In turn, work [21] presents the concept of using active flow control by suction and variations on front geometry of the vehicle to minimize the aerodynamic drag. Theoretically, this approach can be used to minimize the aerodynamic drag for a powerboat hull.

Ground effect vehicles (GEVs) constitute a different type of ships. They use the ground effect, or the phenomenon of aerodynamic interference between the control surfaces and the surface of water. The ground effect studies for wing in surface effect-craft are presented in the paper [20]. These ships have certain advantages, i.e. achieve higher speeds than typical motor boats and show a stable movement even if the water surface ripples a lot. An analysis of the performance of this type of vessels should include the aerodynamic and hydrodynamic phenomena that simultaneously occur while the vessel moves. There are many publications that investigate this kind of structures, e.g. the aerodynamics of a WIG craft moving over the curved ground is investigated in [23], a dynamic model of movement in the vertical plane reflecting aerodynamics, hydrodynamics and the driving forces for ground effect vehicles was studied in [13], a complex mathematical model of movement of this type of vehicles was discussed in [4]. In [12], the authors conducted a hydrodynamical study of a wing-in-ground vehicle by towing tank experiments on a given model and CFD numerical calculations. The examined literature enables us to formulate the methods to create a model for simulation research, and creating such a model should follow in stages: creating a geometric model (by the CAD software), creating a model for simulation (creating a mesh) and preparing a model for research (specifying boundary and initial conditions, etc.). If ANSYS is used, all of these stages can be carried out in its modules.

The second part of the work presents the geometry of the test object and approximates the assumptions made for the needs of preparing the boat model for numerical tests. Attention was paid to the generated computational grid, the division of the boat body into components, and the turbulence model used was briefly characterized. The third paragraph contains a presentation of the results of numerical calculations. The pressure and velocity distributions around the test object in the plane of its symmetry were obtained. In addition, the drag force characteristics as a function of speed and angle of attack were prepared. On this basis, equations were developed 

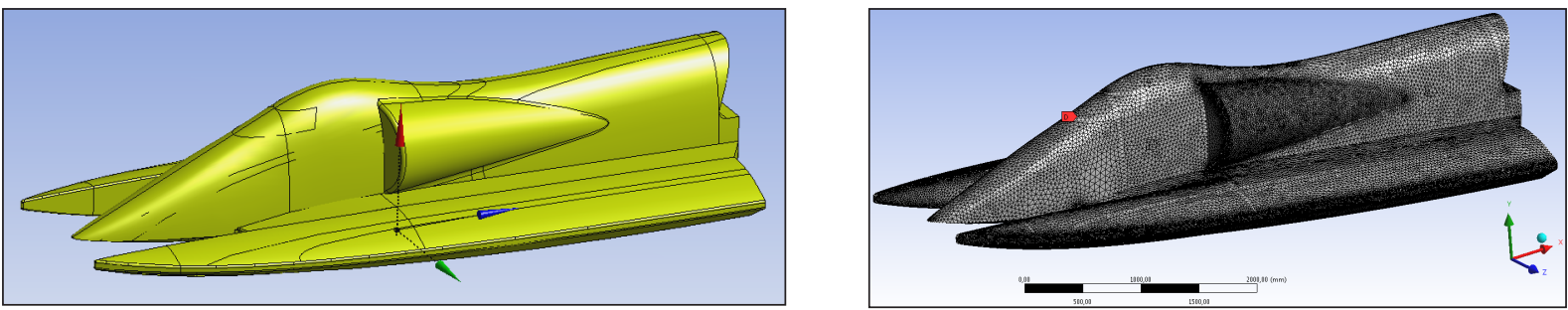

Fig. 1. The solid model of the test object (left) and the generated computational grid of the test object (right)

to approximate the drag force as a function of the listed parameters. The last section presents a discussion of the results obtained and a summary of the whole work.

\section{RESEARCH OBJECT AND BOUNDARY CONDITIONS}

The first stage of the simulation tests is preprocessing. First of all, a geometric model of a research object needs to be created by means of the Computer Aided Design software, e.g. Catia. The developed geometry should be discretized. In a simplified form, a discretization of a continuous model involves its transformation into a set (grid) of finite elements. In the case of quite complicated shapes such as an aircraft body, the grid is unstructured with tetrahedral elements. A literature analysis shows that grid generation is usually performed using the ICEM CFD or ANSYS Meshing software. However, the calculations are made using the ANSYS Fluent software. The last step is a presentation and analysis of results by means of the CFD-Post module, i.e. post-processing.

The purpose of this work was to investigate the aerodynamic drag force generated on the individual components of the powerboat. Accordingly, a solid model of the test object was developed using the CAD software, and then numerical calculations for different speeds and different angle of attack between the longitudinal axis of the boat and the water surface were performed. The drag values generated on the individual components of the hull were obtained. The frontal areas of each hull element necessary to calculate drag coefficients were measured on the basis of a solid model created in the CAD software.

The CFD numerical studies of the powerboat were performed using the Ansys Fluent software. The boat model (Fig. 1) was downloaded from the open database of the GrabCAD models. This was a surface model only and contained fragmented surfaces with existing discontinuities, so a complete solid model should be prepared for testing the air flow around the boat. In the next stage, it was necessary to supplement the missing surfaces, so the thickness of the surface of the tested boat was given, i.e. filling with some material. The object prepared in this way was imported into the Design Modeler module where a computational domain was prepared using the enclosure function.

The dimensions of the boat model are $6019 \times 2380 \times 1397 \mathrm{~mm}($ length $\times$ width $\times$ height $)$. The test object was placed in the computational domain with the dimensions of $26019 \times 22380 \times 21397$ mm (length $\times$ width $\times$ height). Figure 1 shows the position of the test object relative to the global coordinate system. The length of the computational domain was 4.3 times the length of the test object. On the walls of the computational domain (Fig. 2), the velocity inlet and the pressure outlet boundary condition were defined. The surface of the object was set as the wall type. The direction of the speed vector $v$ of inflow air coincided with the direction of the longitudinal axis $x$.

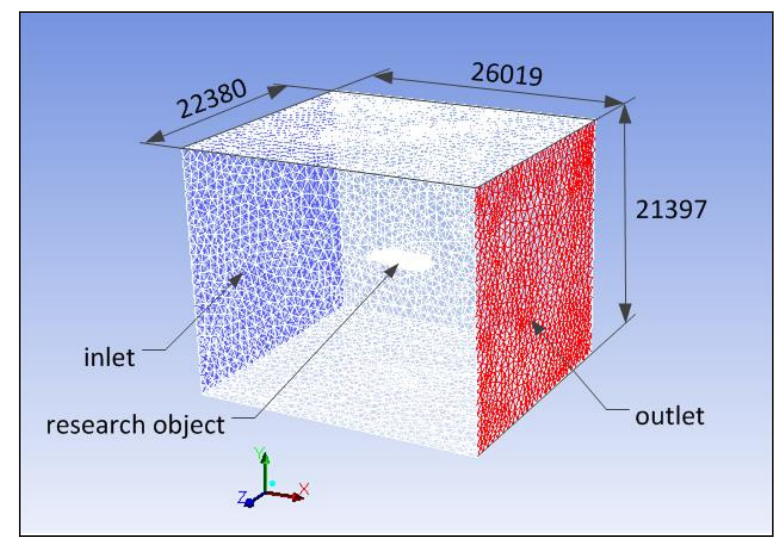

Fig. 2. The research object in the computational domain 
Table 1. Drag force given in [N] on the individual elements of the boat for different angle of attack and speeds

\begin{tabular}{|c|c|c|c|c|}
\hline $\mathbf{v}$ & $15 \mathrm{~m} / \mathrm{s}$ & $30 \mathrm{~m} / \mathrm{s}$ & $45 \mathrm{~m} / \mathrm{s}$ & $60 \mathrm{~m} / \mathrm{s}$ \\
\hline \multicolumn{5}{|c|}{$\alpha=0^{\circ}$} \\
\hline wall_1 & 32.22 & 126.40 & 287.40 & 504.60 \\
\hline wall_2 & 8.94 & 35.33 & 79.17 & 140.80 \\
\hline wall_3 & 27.73 & 108.60 & 245.60 & 429.50 \\
\hline wall_4 & 24.86 & 99.42 & 222.50 & 406.00 \\
\hline Total & 93.75 & 369.75 & 834.67 & 1480.90 \\
\hline \multicolumn{5}{|c|}{$\alpha=3^{\circ}$} \\
\hline wall_1 & 31.45 & 124.20 & 277.50 & 484.10 \\
\hline wall_2 & 10.38 & 40.81 & 91.88 & 165.10 \\
\hline wall_3 & 32.33 & 127.70 & 286.40 & 491.20 \\
\hline wall_4 & 25.28 & 100.40 & 228.50 & 416.40 \\
\hline Total & 99.44 & 393.11 & 884.28 & 1556.80 \\
\hline \multicolumn{5}{|c|}{$\alpha=6^{\circ}$} \\
\hline wall_1 & 34.33 & 135.90 & 304.30 & 540.20 \\
\hline wall_2 & 14.43 & 57.10 & 127.80 & 226.20 \\
\hline wall_3 & 41.14 & 161.90 & 361.20 & 638.30 \\
\hline wall_4 & 24.99 & 99.08 & 226.80 & 422.20 \\
\hline Total & 114.89 & 453.98 & 1020.10 & 1826.90 \\
\hline \multicolumn{5}{|c|}{$\alpha=9^{\circ}$} \\
\hline wall_1 & 40.09 & 159.20 & 358.10 & 639.40 \\
\hline wall_2 & 20.89 & 82.98 & 186.30 & 330.70 \\
\hline wall_3 & 54.36 & 213.90 & 477.30 & 843.70 \\
\hline wall_4 & 27.09 & 107.50 & 247.10 & 460.60 \\
\hline Total & 142.43 & 563.58 & 1268.80 & 2274.40 \\
\hline \multicolumn{5}{|c|}{$\alpha=12^{\circ}$} \\
\hline wall_1 & 49.69 & 197.70 & 444.20 & 790.80 \\
\hline wall_2 & 30.73 & 122.00 & 274.20 & 488.40 \\
\hline wall_3 & 73.87 & 291.00 & 650.10 & 1152.00 \\
\hline wall_4 & 28.89 & 115.00 & 262.80 & 477.70 \\
\hline Total & 183.18 & 725.70 & 1631.30 & 2908.90 \\
\hline
\end{tabular}

A computational grid (Fig. 1) consisting of 3973460 elements 4-Node Linear Tetrahedron type (Tet4) and 6-Node Linear Wedge type (Wed6) was generated for the prepared model. The model was divided into four sections: wall_1, wall_2, wall_3, wall_4 which correspond to the hull, hull connectors, floats and air intakes. In addition, for the entire boat using the Inflation function, a boundary layer consisting of 6 sub-layers with a growth rate equal to 1.2 and a transition ratio of 0.272 was defined. Mesh concentration using the face sizing function was applied on the selected surfaces of the model.
The turbulence model $k$ - $\omega$ SST with an activated compressibility effect and an energy equation was adopted for the calculations. This model efficiently approximates the turbulent flow near the boundary layer and also remains sensitive to the turbulence occurring in the free flow. It is a combination of two models: $k-\varepsilon$ and $k-\omega$. Turbulence was determined by a turbulent intensity equal to $1 \%$ and a turbulent viscosity ratio equal to 5 .

The pressure-based calculations for fixed conditions were defined. It was assumed that the air flowing around the tested model is an ideal gas with a temperature of $15^{\circ} \mathrm{C}$, density $1.225702 \mathrm{~kg} / \mathrm{m}^{3}$ and viscosity of $1.7894 \cdot 10^{-5} \mathrm{~kg} /(\mathrm{ms})$.

For the selected solver settings, a series of calculations were made for the velocity values $v$ equal to $15,30,45,60 \mathrm{~m} / \mathrm{s}$ as well as angle of attack between the longitudinal axis of the boat and the water surface $\alpha$ equal to $0,3,6,9,12^{\circ}$.

\section{RESULTS}

The calculations gave the values of the drag force generated on particular boat elements for the adopted combinations of speed $v$ and angle of attack $\alpha$. The results are shown in Table 1 .

Figure 3 shows the map of the drag force generated on the body of the tested boat as a function of two parameters: air velocity and the angle of attack from the water surface. The drag force increases along with the speed and the angle of attack; its highest value is reached at $60 \mathrm{~m} / \mathrm{s}$ and the angle equal to $12^{\circ}$.

Figure 4 shows the pressure contour on the surface of the model and in the plane of symmetry

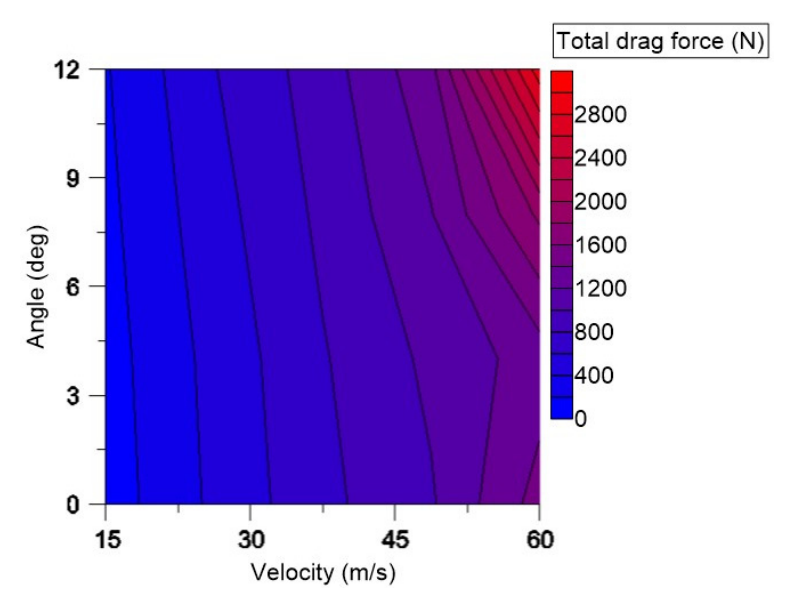

Fig. 3. Drag force map for the defined speeds and angle of attack 

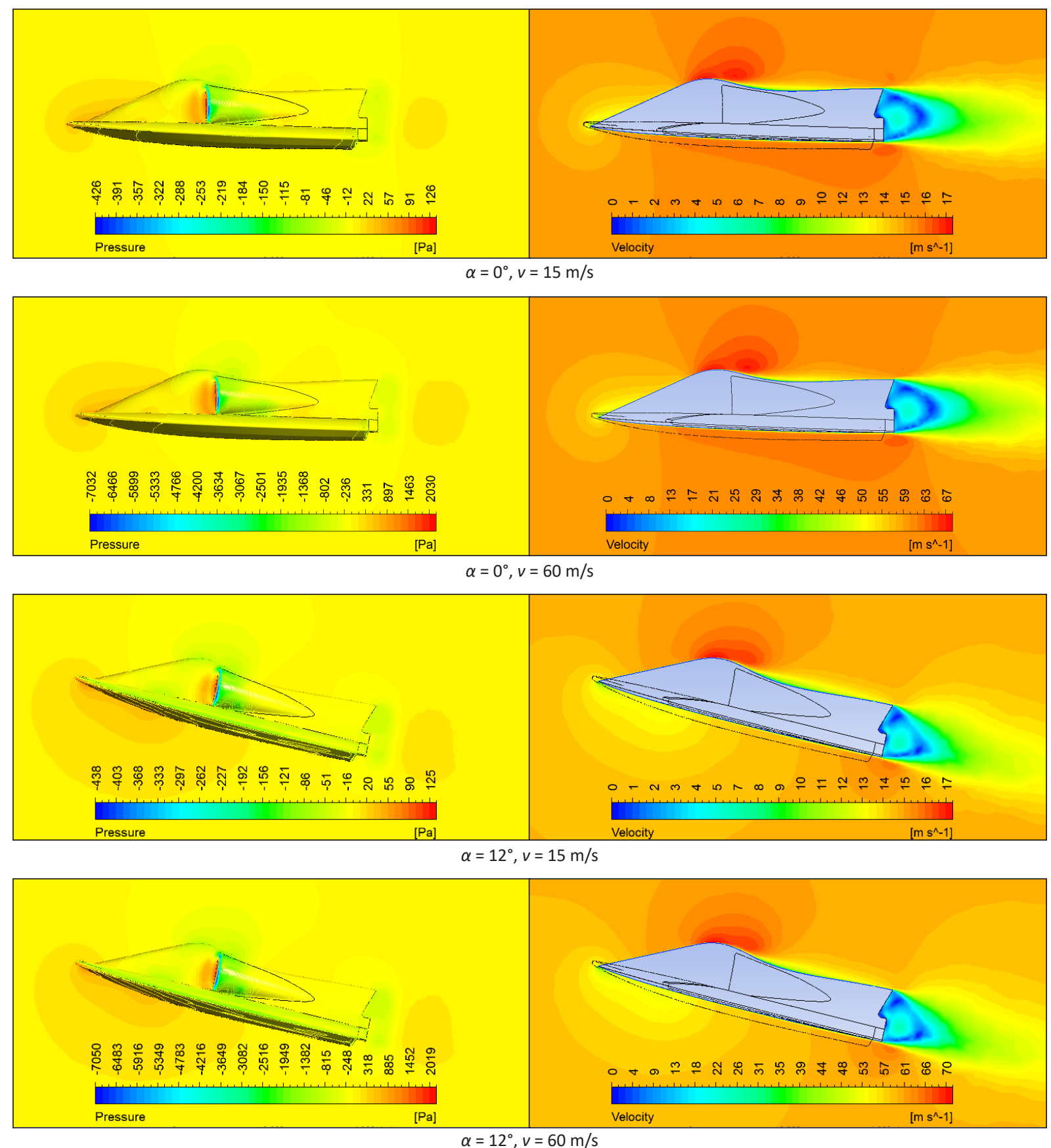

Fig. 4. Pressure contours on the surface of the model and in the plane of symmetry (left) and velocity contours in the plane of symmetry (right) for extreme combinations of angle of attack $\alpha$ and velocities $v$

and the velocity contour in the plane of symmetry for the extreme combinations of angle of attack $\alpha$ and velocities $v:\left(\alpha=0^{\circ}, v=15 \mathrm{~m} / \mathrm{s}\right)$, $\left(\alpha=0^{\circ}, v=60 \mathrm{~m} / \mathrm{s}\right),\left(\alpha=12^{\circ}, v=15 \mathrm{~m} / \mathrm{s}\right)$, $\left(\alpha=12^{\circ}, v=60 \mathrm{~m} / \mathrm{s}\right)$. The negative values in the pressure contour diagrams correspond to the gauge pressure.

Figure 5 shows the total drag force as a function of the velocity of the airflow for different angle of attack $\alpha$. For the points plotted, the trend lines in the form of second order polynomials with the equations presented in Table 2 were plotted. Figure 6 shows the drag force generated on the individual boat elements for different angle of attack $\alpha$ for extreme airflow velocities $v=15 \mathrm{~m} / \mathrm{s}$ and $v=60 \mathrm{~m} / \mathrm{s}$.

\section{DISCUSSION}

For a constant $\alpha$ angle, the drag force increases along with the velocity and is proportional to 
Table 2. Equations of the plotted trend lines

\begin{tabular}{|c|c|c|c|}
\hline Angle of attack $\boldsymbol{\alpha}\left({ }^{\circ}\right)$ & $\begin{array}{c}\text { Second degree approximation } \\
\text { function } \boldsymbol{F}=\boldsymbol{F}(\boldsymbol{v})\end{array}$ & Air velocity $\mathbf{v}(\mathbf{m} / \mathbf{s})$ & $\begin{array}{c}\text { Second degree approximation } \\
\text { function } \boldsymbol{F}=\boldsymbol{F}(\boldsymbol{\alpha})\end{array}$ \\
\hline 0 & $\mathrm{y}=0.8168 \mathrm{x}^{2}-0.7049 \mathrm{x}+10.43$ & - & - \\
\hline 3 & $\mathrm{y}=0.6494 \mathrm{x}^{2}-1.3633 \mathrm{x}+17.583$ & 15 & $\mathrm{y}=10.275 \mathrm{x}^{2}-4.1752 \mathrm{x}+1479.8$ \\
\hline 6 & $\mathrm{y}=0.5045 \mathrm{x}^{2}-0.097 \mathrm{x}+2.83$ & 30 & $\mathrm{y}=5.8624 \mathrm{x}^{2}-4.4226 \mathrm{x}+837.8$ \\
\hline 9 & $\mathrm{y}=0.4209 \mathrm{x}^{2}+0.8508 \mathrm{x}-8.8425$ & 45 & $\mathrm{y}=2.5893 \mathrm{x}^{2}-1.6591 \mathrm{x}+371.36$ \\
\hline 12 & $\mathrm{y}=0.4114 \mathrm{x}^{2}-0.01 \mathrm{x}+0.9625$ & 60 & $\mathrm{y}=0.6525 \mathrm{x}^{2}-0.4345 \mathrm{x}+94.112$ \\
\hline
\end{tabular}
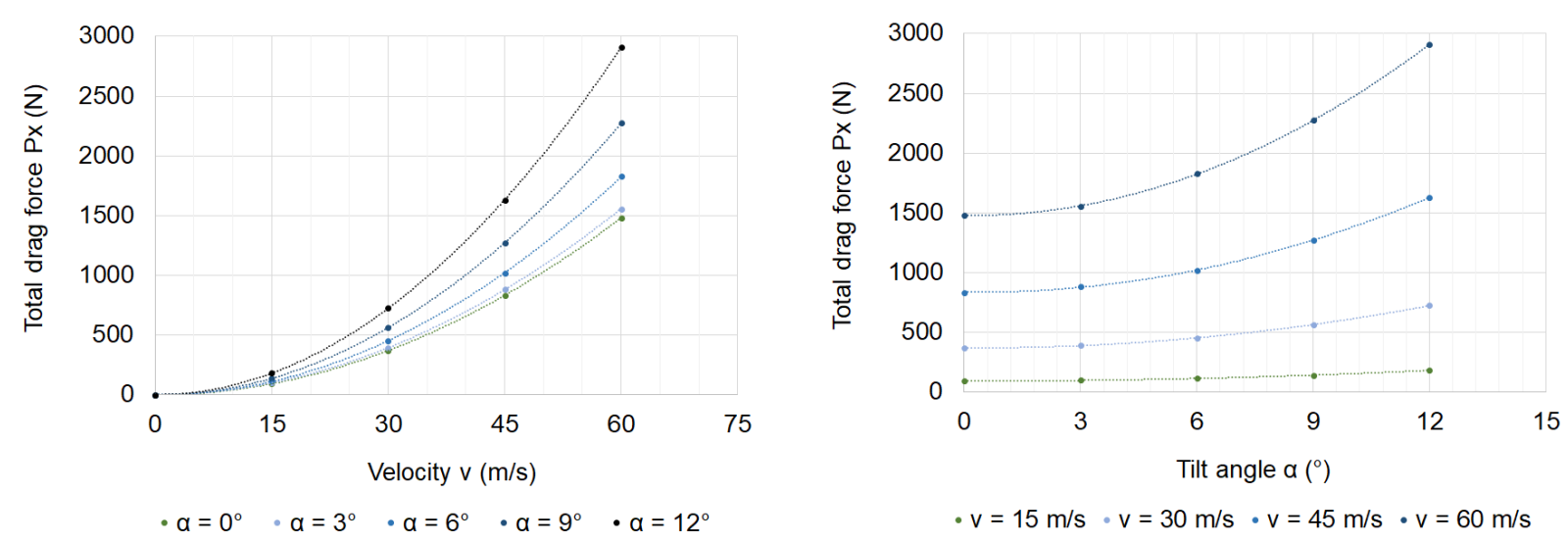

Fig. 5. Total drag force as a function of: the velocity of flowing air $v$ for different angle of attack $\alpha$ (left) and the angle of attack $\alpha$ for different velocities of flowing air (right)
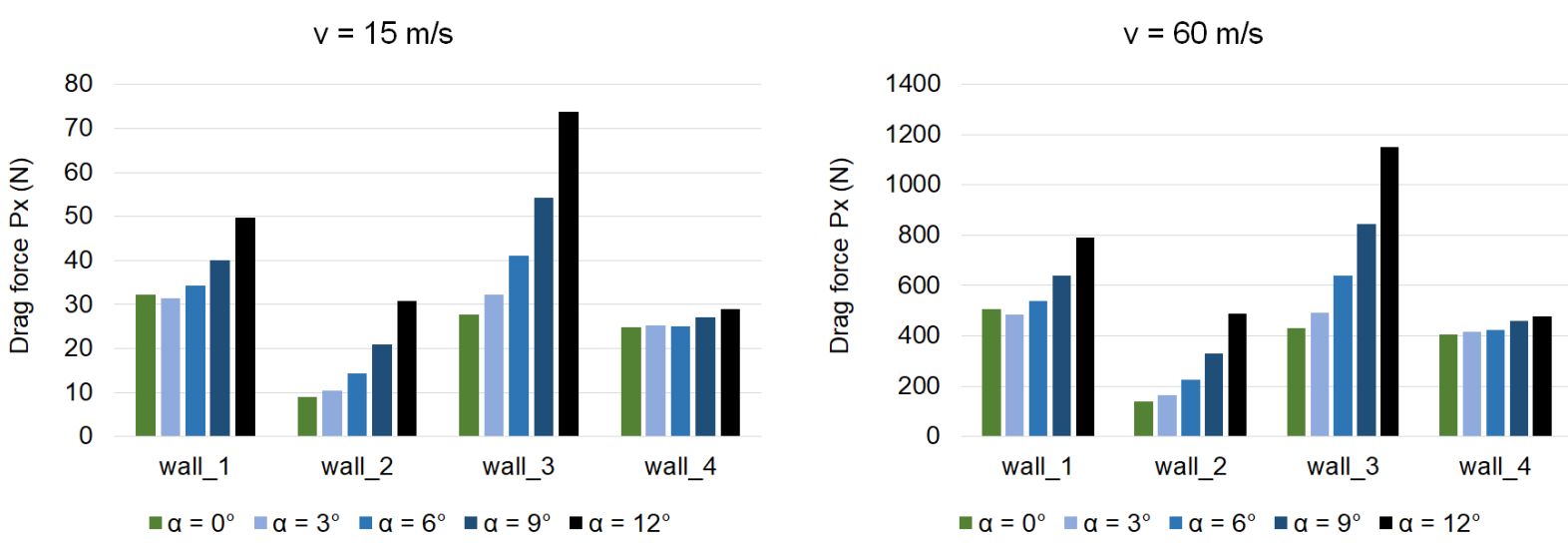

Fig. 6. The drag force generated on the individual boat elements for different angle of attack for speeds: $v=15 \mathrm{~m} / \mathrm{s}$ (left) and $v=60 \mathrm{~m} / \mathrm{s}$ (right)

the square of the velocity. For a low velocity equal to $15 \mathrm{~m} / \mathrm{s}$, the drag forces on individual elements amount to several dozen newtons, while the total drag force does not exceed $200 \mathrm{~N}$, regardless of the angle of attack $\alpha$. For very high velocities, the forces increase significantly, and for $v=60 \mathrm{~m} / \mathrm{s}$, they amount to several hundred newtons on individual elements, and the total drag force depending on the angle $\alpha$ has a value in the range of $1480-2908 \mathrm{~N}$.
For velocity $v=15 \mathrm{~m} / \mathrm{s}$ and the angles of attack $\alpha$ equal to $0^{\circ}$ and $12^{\circ}$, the highest gauge pressure is -426 and $-438 \mathrm{~Pa}$, respectively. The largest increase in pressure occurs on the nose of the boat and the air intakes, amounting to approx. $-125 \mathrm{~Pa}$. For speed $v=60 \mathrm{~m} / \mathrm{s}$, the gauge pressure value increases to approx. $-7000 \mathrm{~Pa}$, and the maximum pressure accumulation at the air inlets is approx. $2000 \mathrm{~Pa}$. The highest acceleration of air occurs on the upper 
part of the hull. The air moves at the lowest velocity in the rear section, behind the engine. A change in the angle of attack hardly affects the extreme pressure and velocity values.

For a low speed $(v=15 \mathrm{~m} / \mathrm{s})$, the change in $\alpha$ slightly changes the drag force generated on wall_4, because the frontal area of the inlets remains large and relatively flat despite the variation of the angle of attack. However, the drag force on wall_1, wall_2 and wall_3 significantly changes because the separation of the air streams appears earlier at large angle of attack angles and the air pushes perpendicularly against larger frontal areas. Analogously, for a very high speed $(v=60 \mathrm{~m} / \mathrm{s})$, the values of the forces generated are about 20 times greater.

For a small angle of attack $\alpha=3^{\circ}$, wall_1, wall_2 and wall_3 have the largest share in drag generation, i.e. 34,30 and $27 \%$, respectively. With the increase of the angle of attack, the drag force generated on wall_3 increases but on wall_2 and wall 4 it decreases. For the angle of attack $\alpha=$ $12^{\circ}$, the percentages for wall_1, wall_4, wall_4 and wall_4 are $27,17,40$ and $16 \%$, respectively.

On the basis of Figure 3 (map), it was found that the airflow velocity is a decisive factor behind the increase of the drag force under the considered conditions. This is evidenced by almost vertical isolines. For extremely high velocity values (above $50 \mathrm{~m} / \mathrm{s}$ ), drag force isolines curved, indicating a greater effect of the angle of attack.

\section{CONCLUSIONS}

There are few papers on the aerodynamic analysis of motor sports boats. However, no numerical analysis of the impact of angle of attack and velocity on drag force was presented. In this work, the velocity and pressure distribution around the test object in the plane of its symmetry obtained as a result of calculations was analyzed. In addition, the results of numerical calculations allowed the development of the drag force maps. The drag forces acting on individual components of a powerboat for various combinations of velocity and the angle of attack of the boat to the water surface were also obtained. At zero angle of attack, the area of overpressure arises above the bow of the boat, while for the positive angles, this area occurs below its bow. High positive pressure, in turn, occurs on the frontal surfaces such as the nose of the boat and engine air intakes. The highest flow velocity around the hull is induced at the top of the hull due to the streamlined shape that accelerates the flow according to the Bernoulli's law. In addition, an increase in speed occurs at the trailing edge of the bottom of the boat. The developed drag force map shows that the generated drag force is the highest for the angle of attack of $12^{\circ}$ and a speed of $60 \mathrm{~m} / \mathrm{s}$. As these values decrease, the strength decreases, where it is visible on the map in the form of vertically-diagonal isolines. The engine air intakes generated comparable drag for the given angle of attack for a given air velocity. For hull connectors and floats, the increase was of a similar nature. The increase in the drag force on hull as the angle of attack increased was smaller. Floats had the largest share in the generation of the aerodynamic drag $(40 \%$ of the total drag force for $\alpha=12^{\circ}$ ). The hull also had a significant share $(27 \%$ of the total drag force for this test point). The drag generated on hull connectors and air inlets was comparable and amounted to 16 and $17 \%$ of the total drag force, respectively.

In further studies, it would be possible to examine how the aerodynamic drag is impacted by the interaction between a boat and two fluids, i.e. air and water. It would also be possible to determine the drag coefficients based on the measured frontal areas of individual boat structure elements.

\section{REFERENCES}

1. Abdul Manaf M., Mat S., Mansor S., Nasir M., Mat Lazim T., Wan Ali W., Wan Omar W., Mohd. Ali, Z., Abdul-Latif A., Abd. Wahid M., Dahalan M., Othman N. Wind Tunnel Experiment of UTM-LST Generic Light Aircraft Model with External Store, International Review of Mechanical Engineering, 12(3), 2018, 263-271.

2. Basheer Faraj M., Aftab S., Mustapha F., Ariffin M., Ahmad K. Numerical Studies on Heat Ventilation Air Conditioning (HVAC) System in Operation Theaters: a Review, International Review of Mechanical Engineering, 12(7), 2018, 635-641.

3. Belfkira Z., Mounir H., El Marjani A., Comparison of Experimental and Numerical Performances of a Wind Turbine Airfoil Using XFOIL and Computational Fluid Dynamics Simulation, International Review on Modelling and Simulations, 12(4), 2019, 212-221.

4. Benedict K., Kornev N., Meyer M., Ebert J. Complex mathematical model of the WIG motion in- 
cluding the take-off mode. Ocean Engineering, 29(3), 2002, 315-357.

5. Berrini E., Mourrain B., Roux Y., Durand M., Fontaine G. Geometric Modelling and Deformation for Shape Optimization of Ship Hulls and Appendages. Journal of Ship Research, 61(2), 2017, 91-106.

6. Czyż Z., Karpiński P., Łusiak T., Szczepanik T. Numerical analysis of the influence of particular autogyro parts on the aerodynamic forces. ITM Web of Conferences, 15(07008), 2017.

7. Czyż Z., Magryta P., Szlachetka M. Experimental investigation of the impact of flight speed on drag force in the autogyro model. Advances in Science and Technology. Research Journal, 9(26), 2015, 89-95.

8. Czyż Z., Stryczniewicz W. Investigation of aerodynamic interference in a multirotor by PIV method, Advances in Science and Technology. Research Journal, 12(1), 2018, 106-114.

9. Grm A. Mathematical Model For Riverboat Dynamics, Brodogradnja: Teorija i praksa brodogradnje i pomorske tehnike, 68(3), 2017, 25-35.

10. He J., Hu Y., Tang J., Xue S. Research on sail aerodynamics performance and sail-assisted ship stability. Journal of Wind Engineering and Industrial Aerodynamics, 146, 2015, 81-89.

11. Jalasabri J., Romli F. Computational Fluid Dynamics (CFD) Study on a Hybrid Airship Design, International Review of Mechanical Engineering, 11(8), 2017, 573-579.

12. Khoo B.C., Koe H.B. The hydrodynamics of the WIG (Wing-In-Ground) effect craft. 6th International Conference on Underwater System Technology: Theory and Applications (USYS), IEEE, 2016, 195-200.

13. Matveev K.I.. Modeling of longitudinal motions of a hydroplane boat. Ocean Engineering, 42, 2012, 1-6.
14. Muscari R., Dubbioso G., Viviani M., Di Mascio A.. Analysis of the asymmetric behavior of propeller-rudder system of twin screw ships by CFD. Ocean Engineering, 143, 2017, 269-281.

15. Neuberg O., Drimer N. Fatigue limit state design of fast boats, Marine Structures, 55, 2017, 17-36.

16. Pietrykowski K., Tulwin T. Aircraft Radial Engine CFD Cooling Model. SAE International Journal of Engines, 8(1), 2015, 82-88.

17. Prada Botia G., Valencia Ochoa G., Duarte Forero J. CFD Analysis of Hydraulic Performance in Small Centrifugal Pumps Operating with Slurry, International Review on Modelling and Simulations, 12(6), 2019, 364-372.

18. Sarkar P., Haan J.F., Design and Testing of ISUAABL Wind and Gust Tunnel, International Journal on Engineering Applications, 4 (1), 2016, 16-26.

19. Seeni A., Rajendran P. Numerical Validation of NACA 0009 Airfoil in Ultra-Low Reynolds Number Flows, 12(2), 2019, 83-92.

20.Syamsuar S., Djatmiko E., Wilson P., Subchan E. The flight performance criteria for adaptive control design during hydro planing and ground effect altitude of wing in surface effect craft, International Review of Aerospace Engineering, 6(5), 2013, 220-232.

21. Tarakka R., Salam N., Jalaluddin J., Ihsan M. Active Flow Control by Suction on Vehicle Models with Variations on Front Geometry, International Review of Mechanical Engineering 12(2), 2018, 128-134.

22. Wang J., Zou L., Wan D. CFD simulations of free running ship under course keeping control. Ocean engineering, 141, 2017, 450-464.

23. Yang W., Ying C., Yang Z. Aerodynamic study of WIG craft near curved ground. Journal of Hydrodynamics, Ser. B, 2(5), 2010, 371-376. 